\title{
Comparison of Bier's block with Lidocaine versus Lidocaine plus Verapamil
}

Tabdar S', Lama S', Kadariya ER

${ }^{1}$ Assistant Professor, ${ }^{2}$ Lecturer, Department of Anaesthesiology and Intensive Care Kathmandu Medical College Teaching Hospital, Kathmandu, Nepal ${ }^{3}$ Lecturer, Trichandra Multiple Campus, Tribhuvan University, Kathmandu, Nepal.

\section{Abstract}

Background: General anaesthesia and regional anaesthesia both are used for upper extremity surgeries. Bier's Block using local anaesthetic alone or in combination with other adjuvants provides effective analgesia intraoperatively as well as postoperatively with fewer complications as compared to general anaesthesia.

Objective: This study was designed to compare effectiveness, haemodynamic alterations and total duration of analgesia with Lidocaine versus Lidocaine plus Verapamil in Bier's Block.

Methods: This is a prospective randomised double blind trial conducted in Kathmandu Medical College Teaching Hospital from February 2012 to December 2012 after approval from the ethical committee and informed consent from the participants. Total 40 adult patients of age 20 to 50 years, weight 50 to $70 \mathrm{~kg}$, of both gender, belonging to American Society of Anaesthesiologists Physical Status I and II undergoing elective distal upper extrimity surgery lasting at one to one and half hours with Bier's Block were included in this study. They were randomly divided into two groups of twenty each to receive either $40 \mathrm{ml}$ of $0.5 \%$ Lidocaine alone (Group A) or $40 \mathrm{ml}$ of $0.5 \%$ Lidocaine plus $2.5 \mathrm{mg}$ Verapamil (Group $B)$. The two groups were compared in terms of onset and recovery from sensory and motor blockade, tourniquet pain tolerance time, duration of analgesia, alteration of haemodynamics and major side effects. Data analysis was done by Microsoft Office Excel 2007 [Polystat, Microsoft Office Excel worksheet.XLS] using student's two tailed t test. Categorical paramatres were tested by Fisher Exact test and p-value of $<0.05$ was considered statistically significant.

Result: Onset of sensory blockade was faster in group B (Mean \pm SD: $3.07 \pm 0.25$ minutes) as compared to group A (Mean \pm SD: $5.59 \pm 0.41$ minutes). The onset of motor block in group $B$ was $10.4 \pm 0.77$ minutes versus $13.17 \pm 1.45$ minutes in group A. Recovery of sensory block in group $B$ occurred at $29.95 \pm 6.96$ minutes versus $11.45 \pm 2.16$ minutes in group A. Similarly recovery of motor block in group $B$ occurred in $13.6 \pm 1.79$ minutes versus $7.65 \pm 1.04$ minutes in group $A$. Tolerance of first tourniquet pain in group $B$ was long $41.15 \pm 3.82$ minutes versus $22.00 \pm 2.9$ ) minutes in group $A$. Second tourniquet pain tolerance time was again longer (48.25 \pm 3.96 minutes) in group B versus $28.05 \pm 4.84$ minutes in group A. Total duration of analgesia was more in group B ( $207.25 \pm 21.1$ minutes) versus $32.2 \pm 5.78$ minutes in group A. Total consumption of analgesic (Tramadol) in 24 hours in group B was lesser than group A ( $47.5 \pm 38.0$ mg versus $112.5 \pm 35.8$ $\mathrm{mg}$ ). All these differences were significant statistically ( $p$ value $<0.05$ ). Both of the groups showed stable haemodynamic parameters intraoperatively as well as postoperatively without any significant adverse effects.

Conclusion: Addition of Verapamil to Lidocaine was more effective than Lidocaine alone in Bier's block.

Key words: Bier's block, Lidocaine, Verapamil.

\section{INTRODUCTION}

B

ier's block is a frequently used intravenous regional anaesthesia techniques for the operations of hand

\section{Address for correspondence}

Dr. Sushila Tabdar

Assistant Professor

Department of Anaesthesiology and Intensive Care

Kathmandu Medical College Teaching Hospital

Kathmandu, Nepal

Email: sutabdar@yahoo.co.in and forearm using local anaesthetic solution. It was first used in 1908 by German surgeon August KG Bier for the upper limb surgery by injecting Prilocaine intravenously after arterial occlusion of the operating limb with a tourniquet. This procedure gained maximum popularity in the 1960's when Holmes used Lidocaine instead of Prilocaine ${ }^{1}$. Lidocaine is the most commonly used local anaesthetic worldwide. The advantages of Bier's Block with Lidocaine include fast onset, simplicity, reliability, cost effectiveness and avoidance of unnecessary 
complications of general anaesthesia. On the other hand disadvantages includes local anaesthetic toxicity, poor muscle relaxation, early tourniquet pain, short duration of analgesia and possibility of nerve damage if used for a prolong period of time. In a review of 20 year experience by Brown E et al, Bier's block with Lidocaine performed in 1906 patients was shown to be safe and effective than general anaesthesia without any mortality and major morbidity in which adverse reaction mentioned was $1.6 \%$ which consisted of transient dizziness and bradycardia ${ }^{2}$. Keeping these points in mind later on anaesthesiologists modified this technique with the addition of various adjuvants along with Lidocaine to facilitate onset and prolong postoperative analgesia but not all of them were successful due to their side effects which limited their use.

Very recently anaesthesiologists are interested in $L$ type calcium channel blocker Verapamil which is used as an adjuvant along with Lidocaine in regional anaesthesia. This drug has been found to potentiate analgesia of Lidocaine by blocking fast sodium channel in addition to calcium channel. From various experimental studies of Verapamil used as an adjuvant with Lidocaine in regional anaesthesia techniques in humans and animals, this drug has been found successful in modifying sensory onset plus duration of analgesia in central and peripheral nerves without major side effects. In an invitro experiment in rats by Hara Ket al, Verapamil showed its antinociceptive effects on somatic and visceral stimuli when used intrathecally ${ }^{3}$. In another study conducted in humans by Omote et al spinal Verapamil with Lidocaine produced potent and prolonged pain relief with motor block ${ }^{4}$. Choe et al demonstrated that addition of Verapamil to Bupivacaine for epidural anaesthesia resulted less consumption of analgesic postoperatively ${ }^{5}$.

Capt GP et al showed that Verapamil in addition to Lidocaine for brachial plexus block prolonged onset of sensory anaesthesia without any effect on total analgesic duration ${ }^{6}$. The possible important side effects with Verapamil could be vasodilation, hypotension, bradycardia especially in patients already taking antihypertensives and antiarryhmics. Our hypothesis is that Verapamil when used as an adjuvant to Lidocaine can modify onset as well as duration of analgesia in Bier's block.

\section{METHODS}

This was a randomised prospective double blind trial, conducted in Kathmandu Medical College Teaching Hospital from February 2012 to December 2012 after obtaining permission from the Ethical Committee and informed consent from the patients. The patients selected were of age 20 to 50 years, weight 50 to $70 \mathrm{~kg}$, and of both gender, belonging to American Society of Anaesthesiologist (ASA) class I and II posted for elective upper limb surgery under Bier's Block lasting one to one and half hours. The exclusion criteria were those not meeting above characteristics, history of allergy to local anaesthetic solution and Verapamil, coagulation abnormalities, patients using antihypertensives, antiarrythmics, patients with significant bradycardia, hypotension, sickle cell anemia, Raynauds disease. Total 40 patients fulfilling above criteria were equally divided into two groups of twenty each. Group A received $40 \mathrm{ml}$ of $0.5 \%$ Lidocaine and group $B$ received $40 \mathrm{ml}$ of $0.5 \%$ Lidocaine plus Verapamil $2.5 \mathrm{mg}$. The anaesthesiologist who performed Bier's Block was blinded to the group the patient belonged to. All the patients were premedicated with tablet Diazepam $10 \mathrm{mg}$ one night before the operation. After arriving to the operation theatre basic standard monitors used for each patients were Heart Rate (HR), Electrocardiography (ECG), Arterial Oxygen Saturation $\left(\mathrm{SPO}_{2}\right)$ and Noninvasive Blood Pressure(NIBP). At first, the operating upper limb was cannulated with 22 gauge intravenous cannula at the wrist; the non-operating upper limb was cannulated with 18 gauge intravenous cannula for intravenous fluid infusion. The operating limb was then lifted for five minutes to exsanguinate blood and then Esmarch bandage was applied for complete exsanguination of blood after which two tourniquets were applied on the arm one distal to the other. First, proximal tourniquet was inflated up to $250-300 \mathrm{mmHg}$ after which prepared solution was administered intravenously slowly over two minutes. Surgery was allowed to proceed with the single tourniquet till the patient became pain free. The second tourniquet was inflated and the first deflated only when the patient felt pain before surgery was complete or when the first tourniquet inflation time exceeded 30 minutes. The second tourniquet was deflated when the surgery was complete, with total duration not exceeding one and half hours. Injection Midazolam $2 \mathrm{mg}$ was administered to all the patients intravenously while starting the operation. The rescue analgesia used was injection of Tramadol $1 \mathrm{mg} / \mathrm{kg}$ whenever demanded intraoperatively or post operatively.

The paramaters recorded were time for onset of sensory blockade, sensory recovery after deflation of tourniquets (which were assessed at 30 second interval using 25 guage short bevel needle prick for median nerve at thenar eminence, ulnar nerve at hypothenar eminence 
and first web space for radial nerve). Onset of motor blockade and motor recovery time was assessed by asking the patient to flex and extend his/her wrist. Motor blockade was considered complete when the patient could not do any voluntary movement and incomplete when patient could perform supination and pronation of hand. Pain (tourniquet or postoperative) was assessed using $10 \mathrm{~cm}$ marked visual analogue scale (VAS) where zero meant no pain, five meant moderate pain and ten meant severe pain. Other parameters recorded were haemodynamic (PR, NIBP, $\mathrm{SPO}_{2}$ ), first and second tourniquet pain time, total duration of analgesia and side effects.

The data were entered in a Polystat XLS (Microsoft Office Excel Worksheet XLS) software. P-value was calculated by using Student's " $t$ " test (two tailed t test). A p-value of $<0.05$ was considered statistically significant. Categorical parameters were tested by Fisher Exact test and $p$-value of $<0.05$ was considered statistically significant.

\section{RESULTS}

The demographic parameters didn't show any statistically significant differences ( $p$ value $>0.05$ ) as shown in table 1.

There was significant difference in group B as compared to group $A$ in terms of tourniquet pain tolerance times, sensory and motor onset, sensory and motor recovery, total duration of analgesia and requirement of Tramadol (analgesic) in 24 hours $(p<0.05)$ as shown in table 2.

Haemodynamic parameters (Heart Rate, Mean Arterial Pressure) changes were comparable in two groups ( $p>0.05$ ) as shown in table 3 and 4.

Table 1: Patient profile in two groups of the patients

\begin{tabular}{cccc}
\hline Patient profile & $\begin{array}{c}\text { Group A } \\
{[\text { Mean } \pm \text { SD] }}\end{array}$ & $\begin{array}{c}\text { Group B } \\
\text { [Mean } \pm \text { SD] }\end{array}$ & p-value \\
\hline Age (Years) & $35.1 \pm 9.27$ & $37.9 \pm 7.54$ & 0.30 \\
\hline Weight (Kilograms) & $56.5 \pm 4.43$ & $56.15 \pm 4.83$ & 0.81 \\
\hline Gender Ratio (male:female) & $14: 6$ & $12: 8$ & 0.37 \\
\hline
\end{tabular}

$\mathrm{p}$ value calculated by Students " $\mathrm{t}$ " test for age, weight and Fisher Exact test for gender ratio.

Table 2: Two tourniquet pain time, onset of sensory and motor block time, recovery of sensory and motor block time, duration of analgesia and total requirement of Tramadol in 24 hours.

\begin{tabular}{lccc}
\hline $\begin{array}{l}\text { Measured Variables } \\
\begin{array}{l}\text { First Tourniquet pain } \\
\text { (minutes) }\end{array}\end{array}$ & $\begin{array}{c}\text { Group A } \\
{[\text { Mean } \pm \text { SD] }}\end{array}$ & $\begin{array}{c}\text { Group B } \\
{[\text { Mean } \pm \text { SD] }}\end{array}$ & p-value \\
\hline $\begin{array}{l}\text { Second Tourniquet pain } \\
\text { (minutes) }\end{array}$ & $22 \pm 2.9$ & $41.15 \pm 3.82$ & $<0.01$ \\
\hline $\begin{array}{l}\text { Onset of sensory block } \\
\text { (minutes) }\end{array}$ & $28.05 \pm 4.08$ & $48.25 \pm 3.96$ & $<0.01$ \\
\hline $\begin{array}{l}\text { Onset motor block (minutes) } \\
\text { Recovery of sensory block } \\
\text { (minutes) }\end{array}$ & $13.17 \pm 1.47$ & $3.07 \pm 0.25$ & $<0.01$ \\
\hline $\begin{array}{l}\text { Recovery of motor Block } \\
\text { (minutes) }\end{array}$ & $11.45 \pm 2.16$ & $10.4 \pm 0.77$ & $<0.01$ \\
\hline $\begin{array}{l}\text { Duration of analgesia } \\
\text { (minutes) }\end{array}$ & $7.65 \pm 1.04$ & $29.95 \pm 6.96$ & $<0.01$ \\
\hline $\begin{array}{l}\text { Total Tramadol requirement in } \\
24 \text { hours (mg) }\end{array}$ & $32.2 \pm 5.78$ & $13.6 \pm 1.79$ & $<0.01$ \\
\hline
\end{tabular}

$\mathrm{p}$ value calculated by students " $\mathrm{t}$ " test. 
Table 3: Mean arterial pressure at different time intervals following Bier's Block in two study groups.

\begin{tabular}{|cccc}
\hline Time Interval (minutes) & Group A [Mean \pm SD] & Group B [Mean \pm SD] & p-value \\
\hline Base Line & $85.65 \pm 18.21$ & $79.20 \pm 17.23$ & 0.26 \\
5 & $85.15 \pm 16.36$ & $75.20 \pm 17.23$ & 0.07 \\
10 & $88.35 \pm 14.63$ & $78.40 \pm 18.84$ & 0.06 \\
15 & $92.00 \pm 12.25$ & $80.30 \pm 14.85$ & 0.01 \\
\hline 20 & $92.85 \pm 13.76$ & $84.05 \pm 15.48$ & 0.06 \\
25 & $91.50 \pm 13.43$ & $86.70 \pm 15.83$ & 0.31 \\
\hline 30 & $92.55 \pm 14.25$ & $84.60 \pm 14.1$ & 0.08 \\
\hline 5 & $89.55 \pm 12.82$ & $82.5 \pm 13.54$ & 0.09 \\
\hline 40 & $89.60 \pm 13.46$ & $81.45 \pm 13.92$ & 0.10 \\
\hline 5 & $89.45 \pm 13.42$ & $80.15 \pm 13.83$ & 0.04 \\
\hline 55 & $90.20 \pm 14.40$ & $81.25 \pm 15.59$ & 0.07 \\
\hline
\end{tabular}

$\mathrm{p}$ value calculated by students " $\mathrm{t}$ " test.

Table 4: Heart Rate at different time intervals following Bier's Block of two study groups.

\begin{tabular}{cccc}
\hline Time Interval (Minutes) & Group A [Mean \pm SD $]$ & Group B [Mean \pm SD] & p-value \\
\hline Base Line & $75.30 \pm 14.47$ & $78.95 \pm 16.28$ & 0.45 \\
5 & $76.4 \pm 15.23$ & $78.8 \pm 16.34$ & 0.63 \\
10 & $77.10 \pm 14.61$ & $77.75 \pm 16.33$ & 0.89 \\
15 & $75.55 \pm 12.18$ & $95.18 \pm 16.53$ & $<0.01$ \\
\hline 20 & $75.40 \pm 11.89$ & $78.85 \pm 16.56$ & 0.45 \\
25 & $76.75 \pm 12.32$ & $78.50 \pm 16.23$ & 0.70 \\
\hline 30 & $75.35 \pm 10.65$ & $78.20 \pm 15.74$ & 0.50 \\
\hline 35 & $76.25 \pm 11.93$ & $79.20 \pm 14.79$ & 0.49 \\
40 & $75.70 \pm 11.55$ & $79.35 \pm 14.56$ & 0.38 \\
45 & $75.60 \pm 10.78$ & $79.05 \pm 14.61$ & 0.40 \\
\hline 50 & $75.75 \pm 11.47$ & $78.65 \pm 14.42$ & 0.48 \\
\hline 6 & $75.05 \pm 11.89$ & $77.15 \pm 13.32$ & 0.60 \\
\hline
\end{tabular}

$\mathrm{p}$ value calculated by students " $\mathrm{t}$ " test.

\section{DISCUSSION}

The intensity of pain due to upper extremity surgery can vary from patient to patient as mild, moderate or severe depending upon the extent of injury and type of surgery. However with the use of various intravenous systemic analgesics, the intensity of pain has decreased variably in every individual but no one is completely pain free, satisfied and their side effects have limited their use very frequently. Local anaesthetics whose popularity has stepped ahead of systemic intravenous anaesthetics are likened by many anaesthesiologists for a long time and are still popular. The technique of using local anaesthetic along with other adjuvants has become even more popular recently. In various regional anaesthetic techniques local anaesthetics when used in combination with other adjuvant agents, duration of analgesia and quality of analgesia was found to be improved with minimum side effects. So was true for Bier's block. Choyce A et al reviewed various adjuncts in intravenous regional anaesthesia for surgeries ${ }^{7}$. Calcium channel blockers are recently being investigated and found as having antinociceptive effects in both humans and animals from various studies. Nowycky et al in 1985 reported the evidence of three distinct types of calcium channel blockers in sensory neurons namely $\mathrm{L}, \mathrm{T}$ and $\mathrm{N}$ 
types ${ }^{8}$. The $\mathrm{N}$ type is found to be more potent than $\mathrm{L}$ type but due to the neurotoxic effect it could not become useful as an analgesic adjuvant clinically. Nowadays a number of studies have emphasized $\mathrm{N}$ type calcium channel blocker Verapamil as an analgesic drug also in combination with local anaesthetics in various regional anesthetic techniques. Studies in rats have shown that application of Morphine and Verapamil attenuated pain mediated by A delta and $\mathrm{C}$ fibres ${ }^{9}$.

From our study we can say that Verapamil when used as an adjuvant to $0.5 \%$ Lidocaine caused faster onset of sensory block and motor block as compared to $0.5 \%$ Lidocaine alone. Similarly, recovery of sensory and motor block was lengthened in study group of $0.5 \%$ Lidocaine plus verapamil than control $10.5 \%$ Lidocaine) group. First and Second tourniquet pain tolerance time in study group was prolonged than control group. Postoperative analgesia time in study group was increased than control group. Total analgesic consumption (Tramadol) in 24 hours was less in study group than the control group. There was neither hemodynamic instability nor any side effects in the study group intraoperatively as well as postoperatively. In a study by Reuben SS, Steinberg RB and colleagues, Bier's block with $30 \mathrm{mg}$ Ketorolac plus Lidocaine showed analgesia for $585.13 \pm 227.54$ minutes as compared to plain Lidocaine $(113.03 \pm 65.0$ minutes) without side effects and tourniquet pain ${ }^{10}$. Study by Rahman Abbasivash et al showed that when Nitroglycerine 200 $\mu \mathrm{g}$ was used as an adjuvant to Lidocaine, analgesia was obtained for two hours in the post-operative period whereas plain Lidocaine showed analgesia for only half an hour. Onset of tourniquet pain with the addition of Nitroglycerine was prolonged (25 versus 16 ) minutes where $p$ value was 0.05 . Sensory and motor block onsets were shortened in the study group (2.61 versus 5.09 and 4.22 versus 7.04 minutes) respectively. The recovery time of sensory and motor block was lengthened (7.26 versus 3.43 and 9.70 versus 3.74 minutes) ${ }^{11}$. Study by MA Abosedira comparing addition of either Clonidine $1 \mu \mathrm{g} / \mathrm{kg}$ or Dexmeditomidine $1 \mu \mathrm{g} / \mathrm{kg}$ to Lidocaine 3 $\mathrm{mg} / \mathrm{kg}$ showed no significant differences between two groups regarding onset and recovery of sensory and motor blocks but post-operative demand of Fentanyl was $25 \mu \mathrm{g} \pm 11 \mu \mathrm{g}$ ) with Dexmedtomidine group as compared to Clonidine $(32 \mu \mathrm{g} \pm 24.5 \mu \mathrm{g})$ respectively ${ }^{12}$. In another study of 100 patients by Naved Masood et al where Neostigmine $0.5 \mathrm{mg}$ with $3 \mathrm{mg} / \mathrm{kg}$ Lidocaine or simply $3 \mathrm{mg} / \mathrm{kg}$ of Lidocaine showed fast sensory and motor onset in study group (4.14 versus 10 minutes and 6.3 versus 13.3 minutes respectively). Similarly sensory and motor recovery were prolonged in Lidocaine plus Neostigmine group (6.5 versus 3.1 minutes and 5.17 versus 2.17 minutes. Total duration of analgesia in study group was prolonged as compared to the control group (35.3 versus 16.5 minutes) ${ }^{13}$.Acalovschi et al demonstrated that Meperidine had local anaesthetic property on peripheral nerves but side effects limited the use and postoperative analgesia did not exceed five hours $^{14}$. Bier's Block by Turan A et al in 30 patients using a mixture of $10 \mathrm{ml}$ of $15 \%$ Magnesium Sulphate $+3 \mathrm{mg} / \mathrm{kg}$ Lidocaine to a total volume $40 \mathrm{ml}$ or $10 \mathrm{ml}$ normal saline (NS ) $+3 \mathrm{mg} / \mathrm{kg}$ Lidocaine $40 \mathrm{ml}$ showed sensory, motor onset shorter in study group than the control group. Score for tourniquet pain was less at $(15,20,30,40,50)$ min in the study group. First analgesic requirement for Lidocaine plus Magnesium Sulphate was (155 \pm 38) $\mathrm{min}$ versus $(95 \pm 29)$ min in Lidocaine group ${ }^{15}$.

Various studies showed various results regarding sensory, motor onset, tourniquet pain quality and tolerance time, regression of sensory and motor block after tourniquet release and postoperative analgesia with Bier's Block using Lidocaine plus different adjuvants. Our study showed improved results in all the above parameters where $p$ value was $<0.05$. So we can say that $2.5 \mathrm{mg}$ Verapamil added to $40 \mathrm{ml}$ 0.5\% Lidocaine for Bier's block was better with regards to sensory and motor onset, first and second tourniquet pain tolerance time and finally duration of analgesia without any haemodynamic instability.

\section{CONCLUSION}

Verapamil $2.5 \mathrm{mg}$ added to $40 \mathrm{ml}$ of $0.5 \%$ Lidocaine for Bier's block is more effective than $0.5 \%$ Lidocaine alone.

\section{REFERENCES}

1. Holmes C. Intravenous regional anaesthesia: a useful method of providing analgesia in the limbs. Lancet. 1963;1:245-7.

2. Brown E, James T, Griff M, Robert W. Bier's Block: review of 20 years experience. CJA. 1989;36:307-10.
3. Hara K, Saito Y, Krihara, Y. Antinociceptive effects of intrathecal $L$ type of calcium channel blockers on visceral \& somatic stimuli in rats. Anaesth Analg. 1998;87:382-7.

4. Omote K, Sonada H, Kwamata M. Effects of Verapamil on spinal anaesthesia with local anaesthetics. Anaesth Analg. 1995;80:444-8. 
5. Choe H, Kim JS, Kosh J. Epidural Verapamil reduces analgesic consumption after lower abdominal surgery. Anaesth Analg. 1998;86:786-9.

6. Capt GP, Lalla RK, Nanda HS. Verapamail as an adjunct to local anaesthetic for brachial plexus blocks. Med Anaesth. 2010;66:22-4.

7. Choyce A, Peng C. A systematic review of adjuncts for intravenous regional anaesthesia for surgical procedures. Can J Anaesth. 2002;49(1):32-45.

8. Nowycky MC, Fox AP, Tsein RW. Three types of calcium channel blockers with different calcium agonist sensitivity. Nature. 1985;316:440-3.

9. Pirec V, Charles E, Laurito MD. The combined effect of $\mathrm{N}$ type of calcium channel blockers and morphine on A delta vs C fibres mediated nociception. Anaesth Analg. 2001;92:239-43.

10. Reuben SS, Steinberg RB, Kreitzer JM, Dipurat RM. Bier's Block using lidocaine and ketorolac. Anaesth Analg. 1995;81:100-3.
11. Sen S, Ugur B, Aydin ON, Ogurlu M, Gursoy F, Savk O. The analgesic effect of nitroglycerine added to lidocaine on Bier's Block. Anaesth Analg. 2006;102:916-20.

12. Abosedira MA. Adding Clonidine or Dexmedetomidine to Lidocaine during Bier's Block a comparative study. J Med Sci. 2008;8(7):660-4.

13. Turan A, Karamanlyoglu B, Memis D, Kaya G, Pamukcu Z. Bier's Block using Prilocaine and Neostigmine. Anaesth Analg. 2002;95:1419-22.

14. Acalovschi I, Cristea T. Bier's Block with Meperidine. Anaesthesiology. 1995;81(3):539-43.

15. Turan A, Memis D, Karamanliglu B, Gular T, Paracu Z. Bier's Block using Lidocaine and Lidocaine plus Magnesium Sulphate. Anaesth Analg. 2005;100:1189-92. 